\title{
Early Mucosal Gastric Cancer with Lymph Node Metastasis
}

\author{
KEISHIRO AOYAGI, SHOJIRO YANO, JUNJI OHTA, ISSEI KODAMA, \\ KIKUO KOUFUJI, ATSUSHI TOYONAGA* AND JINRYO TAKEDA* \\ Departments of Gastroenterology* and Surgery, \\ Kurume University School of Medicine, Kurume 830, Japan
}

Received for publication May 23, 1995

\begin{abstract}
Summary: From 1976 to 1992 , a total of 358 cases of mucosal early gastric cancer (m-cancer) were treated by resection in the First Department of Surgery, Kurume University Hospital. Eight (2.2\%) of these 358 cases of mcancer were associated with lymph node metastasis. In these 358 cases, the mean diameter of the tumor was $2.75 \mathrm{~cm}$, and the mean age was 59.6 years. In the 8 cases of m-cancer with positive lymph node metastasis $(n(+))$, the mean diameter was $5.2 \mathrm{~cm}$ and the mean age was 51.6 years. Seven $(87.5 \%)$ out of the 8 cases of m-cancer with $\mathrm{n}(+)$ were IIc macroscopic cancer type and were associated with ulcer and/or ulcer scar.
\end{abstract}

Key words: adenocarcinoma - mucosal cancer - macroscopical classification ulcer scar - lymph node metastasis

\section{Introduction}

Early gastric cancer (EGC) is defined as a carcinoma confined to the mucosa or submucosa (sm-cancer) of the stomach, with or without lymph node metastasis, according to the Guidelines of the Japanese Research Society for Gastric Cancer (1981). The lymph node metastasis rate is generally recognized to be about $20 \%$ for sm-cancer and 2-5\% for m-cancer (Takeda et al. 1987; Endo and Habu, 1990; Baba et al. 1994). Therefore, endoscopic mucosal resection (EMR) for small $\mathrm{m}$ cancer has become widely accepted as the choice treatment. However, there are a few cases of m-cancer with positive lymph node metastasis $(\mathrm{n}(+))$. We have retrospectively investigated the characteristics of these cases of $n(+)$ m-cancer with the aim of further improving the mucosal cancer therapy for safety and the selection criteria for treatment.

\section{Methods and Results}

From 1976 to 1992, a total of 358 cases of m-cancer underwent resection in the First Department of Surgery, Kurume University Hospital. These 358 patients consisted of 232 males and 126 females with a mean age of 59.6 years old (ranging from 20 to 83 years old). Cases of multiple gastric cancer, such as advanced cancer plus an early cancer, were classified as advanced cancer. Double EGC, such as $\mathrm{m}$-cancer+ sm-cancer, was recognized as the sm-cancer of the deeper infiltration, and then excluded from the present study. The macroscopic classification of EGCs is summarized in Fig. 1. The cor- 
TABLE 1.

Relationship between macroscopic and microscopic type of mucosal cancer

\begin{tabular}{lrrrrrrrrrrrr}
\hline & I & IIa & IIb & IIc & III & IIa+IIc & Ilc+IIa & Ic +Ilb & Ilc+III & III+IIc & Others Total \\
\hline tub 1 & 9 & 59 & 3 & 80 & 1 & 17 & 3 & 0 & 5 & 0 & 5 & 182 \\
tub 2 & 0 & 2 & 1 & 36 & 0 & 2 & 0 & 0 & 3 & 1 & 1 & 46 \\
pap & 1 & 4 & 1 & 0 & 0 & 1 & 0 & 0 & 1 & 0 & 2 & 10 \\
por & 0 & 0 & 0 & 29 & 0 & 0 & 0 & 1 & 6 & 0 & 0 & 36 \\
sig & 0 & 0 & 2 & 57 & 1 & 1 & 1 & 2 & 17 & 1 & 2 & 84 \\
\hline Total & 10 & 65 & 7 & 202 & 2 & 21 & 4 & 3 & 32 & 2 & 10 & 358 \\
\hline
\end{tabular}

tub1: well differentiated tubular adenocarcinoma; tub2: moderately diff. tub. adeno.; pap: papillary adeno.; por: poorly diff. adeno.; sig: signet-ring cell carcinoma

TABLE 2.

Cancer location and tumor size of mucosal cancer

\begin{tabular}{lclc}
\hline Location & $\begin{array}{c}\text { No. of } \\
\text { cases }\end{array}$ & Tumor size & $\begin{array}{c}\text { No. of } \\
\text { cases }\end{array}$ \\
\hline$[\mathrm{M}]$ & 177 & $1.0 \mathrm{~cm} \leqq$ & 33 \\
{$[\mathrm{~A}]$} & 132 & $1.0-2.0 \mathrm{~cm}$ & 96 \\
{$[\mathrm{C}]$} & 25 & $2.0-3.0 \mathrm{~cm}$ & 62 \\
{$[\mathrm{MC}]$} & 9 & $3.0-4.0 \mathrm{~cm}$ & 44 \\
{$[\mathrm{MA}]$} & 6 & $4.0-6.0 \mathrm{~cm}$ & 33 \\
{$[\mathrm{AM}]$} & 2 & $6.0-8.0 \mathrm{~cm}$ & 16 \\
{$[\mathrm{CM}]$} & 2 & $8.0-10.0 \mathrm{~cm}$ & 3 \\
{$[\mathrm{AD}]$} & 2 & $10.0 \geqq$ & 8 \\
{$[\mathrm{CE}]$} & 1 & & \\
{$[\mathrm{MAC}]$} & 1 & Mean $=2.75 \mathrm{~cm}$ & \\
{$[\mathrm{MCA}]$} & 1 & & \\
\hline
\end{tabular}

relation of macroscopic cancer type and pathological classification in $\mathrm{m}$-cancer is summarized in Table 1.

The cancer location and the tumor size in m-cancer are summarized in Table 2. The overall mean tumor diameter was $2.75 \mathrm{~cm}$ (Table 2 ). Only 8 (2.2\%) of these m-cancer had positive lymph node metastasis $(\mathrm{n}(+))$, pathologically. These 8 patients consisted of 4 males and 4 females with a mean age of 51.6 years, and they had a mean tumor size of $5.2 \mathrm{~cm}$ in diameter. Seven $(87.5 \%)$ of these $8 \mathrm{~m}$ cancer with $\mathrm{n}(+)$ cases were depressed type IIc as shown in Table 3.

Seven $(87.5 \%)$ of the 8 tumors were

TABLE 3.

Number of mucosal cancer with lymph node metastasis

\begin{tabular}{|c|c|c|c|c|c|c|c|c|}
\hline $\begin{array}{c}\text { Patient } \\
\text { No. }\end{array}$ & Age & Sex & Location & Size & Macroscopic & Microscopic & $\begin{array}{c}\mathrm{n}(+) \\
\text { number }\end{array}$ & Meta. Node No. \\
\hline 1. & 57 & M & Less & $1.8 \mathrm{~cm}$ & II + III & tub1 & $\mathrm{n} 2$ & No. $8 \mathrm{a}$ \\
\hline 2. & 51 & M & MA Less & $5.5 \mathrm{~cm}$ & IIc & tub2 & n1 & No. 3 \\
\hline 3. & 68 & M & M Less & $2.0 \mathrm{~cm}$ & IIc + III & tub1 & $\mathrm{n} 2$ & No. $8 \mathrm{a}$ \\
\hline 4. & 31 & $\mathrm{~F}$ & CMA Less & $8.0 \mathrm{~cm}$ & IIc + III & sig & $\mathrm{n} 1$ & No. 3 \\
\hline 5. & 51 & $\mathrm{~F}$ & M Ant & $6.5 \mathrm{~cm}$ & IIc & por $>$ sig & $\mathrm{n} 1$ & $(1 / 42)$ \\
\hline 6. & 28 & $\mathrm{~F}$ & Ant & $6.0 \mathrm{~cm}$ & IIc & por $>$ muc & $\mathrm{n} 1$ & No. $3,4 \mathrm{~d}(2 / 41)$ \\
\hline 7. & 75 & $\mathrm{~F}$ & Gre & $1.0 \mathrm{~cm}$ & II & tub1>pap & $\mathrm{n} 1$ & No. $4 d \quad(1 / 6)$ \\
\hline 8. & 52 & M & CM Less & $10.5 \mathrm{~cm}$ & IIc & sig $>$ tub2 & $\mathrm{n} 1$ & No. 3 \\
\hline
\end{tabular}


TABLE 4.

Details of mucosal cancer with $n(+)$

\begin{tabular}{ccclccc}
\hline $\begin{array}{c}\text { Patient } \\
\text { No. }\end{array}$ & Macroscopic & Microscopic & Ulcer & M.m.invasion & Vessel invasion & Intraoperative stage \\
\hline 1. & IIc + III & tub1 & UlIII & unknown & $1 \mathrm{y} 0, \mathrm{v} 0$ & III (H0P0N2S1) \\
2. & IIc & tub2 & UlIIs & unknown & $1 \mathrm{y} 0, \mathrm{v} 0$ & II (H0P0N1S0) \\
3. & Ilc + III & tub1 & UlIII & $(+)$ & $1 \mathrm{y} 0, \mathrm{v} 0$ & III (H0P0N2S0) \\
4. & IIc + III & sig & UlII & $(-)$ & $1 \mathrm{y} 0, \mathrm{v} 0$ & II (H0P0N1S0) \\
5. & IIc & por $>$ sig & UlIIs & $(-)$ & $1 \mathrm{y} 0, \mathrm{v} 0$ & I (H0P0N0S0) \\
6. & IIc & por $>$ muc & UlIIs & $(-)$ & $1 \mathrm{y} 1, \mathrm{v} 0$ & I (H0P0N0S0) \\
7. & II & tub1 $>$ pap & $(-)$ & $(+)$ & $1 \mathrm{y} 1, \mathrm{v} 0$ & I (H0P0N0S0) \\
8. & IIc & sig $>$ tub2 & UlIIs & $(-)$ & $1 \mathrm{y} 0, \mathrm{v} 0$ & I (H0P0N0S0) \\
\hline
\end{tabular}

associated with an ulcer or an ulcer scar. Four (50\%) of the 8 were of mixed pattern type, pathologically. Also 4 (50\%) of the 8 cases had been misdiagnosed as an $n(-)$ intraoperatively as shown in Table 4.

\section{Discussion}

The rate of EGC has been steadily increasing in Japan (Iriyama and Suzuki, 1992). Macroscopically, cases of m-cancer of depressed type were more frequent (71\%) than cases of elevated type (26.8\%). The frequency of flat type was only $2 \%$ in this study.

The standard gastrectomy (D2) which involves gastrectomy, omentectomy and the complete removal of the Group 1 and 2 lymph nodes was generally accepted as the procedure of choice for curative treatment of an EGC. However, lymph node metastasis rate is generally recognized to be present in only $2-5 \%$ for mucosal cancer and was only $2.2 \%$ in the present study. Therefore, endoscopic mucosal resection (EMR) and endoscopic laser therapy has been developed and selected for a small m-cancer, especially for an elevated and differentiated tumor within $2 \mathrm{~cm}$ in diameter (Tanaka et al. 1993; Toyonaga et al. 1993).

Seven $(87.5 \%)$ of the 8 cases of $m$ cancer with $\mathrm{n}(+)$ were IIc type macroscopically and $7(87.5 \%)$ of the 8 were also associated with an ulcer or an ulcer scar in the tumor region, 4 (50\%) were undifferentiated pathological type by Nakamura's classification (1967) and 4 (50\%) were mixed microscopic type such as por plus sig. The mean tumor size over all 358 cases of m-cancer was $2.75 \mathrm{~cm}$, and was $5.2 \mathrm{~cm}$ in those $8 \mathrm{~m}$-cancer cases with $n(+)$. The mean age overall 358 cases was 59.6 years old and over the 8 cases of m-cancer with $\mathrm{n}(+)$ was 51.6 years old. The smallest m-cancer with $\mathrm{n}(+)$ case was type IIa and $1.0 \mathrm{~cm}$ in diameter. However, the tumor was massively invading to the mucosal membrane, with positive lymph vessel invasion, and was of mixed histological type. Sowa et al. (1989) reported that 4 cases of $\mathrm{m}$-cancer with $\mathrm{n}(+)$ were all associated with an ulcer scar, were all IIc type, and 3 (75\%) were poorly-differentiated type.

In the abstracts from the 63rd meeting of Japanese Research Society for Gastric 
Cancer (1994), we counted 533 (2.6\%) cases of m-cancer with $\mathrm{n}(+)$ in the 20,641 cases of m-cancer, and 146/185 (78.9\%) of m-cancer with $\mathrm{n}(+)$ were associated with ulcer or an ulcer scar in the tumor and 136/167 (81.4\%) were undifferentiated cancer type.

It is concluded that treatment can be done by EMR for depressed type m-cancer with no ulcer and no ulcer scar and less than $1 \mathrm{~cm}$ in tumor diameter, and for elevated type m-cancer less than $2 \mathrm{~cm}$ in tumor diameter. However, when there is massive invasion to the mucosal membrane, or lymph vessel invasion observed after EMR, then gastrectomy should be considered even in cases of a small mcancer.

\section{References}

Baba, H., Maehara, Y., Okuyama, T., Orita, H., AnAI, H. et al. (1994). Lymph node metastasis and macroscopic features in early gastric cancer. Hepato-Gastroenterol. 41, 380-383.

Endo, M. and HaBU, H. (1990). Clinical studies of early gastric cancer. Hepato-Gastroenterol. 37, 408-410.

Iriyama, K. and Suzuki, H. (1992). The incidence of early gastric cancer continues to increase in our surgical unit. Int. Surg. 77, 41-43.

Japanese Research Society For Gastric Cancer (1981). The general rules for the gastric cancer study in surgery and pathology. Jpn. J. Surg. 11, 127-139.

Nakamura, K., Sugano, H., Takagi, K. and Fuchigami, A. (1967). Histopathological study on early gastric carcinoma of the stomach. Some considerations on the ulcer-cancer by analysis of 144 foci of the superficial spreading carcinomas. Gann 58, 377-387. (in Japanese)

Sowa, M., Kato, Y., Nishimura, M., Kubo, T., MaEKaWA, H. et al. (1989). Surgical approach to early gastric cancer with lymph node metastasis. World J. Surg. 13, 630-636.

Takeda, J., Нashimoto, K., Machi, J., Hirai, Y., Yoshida, T. et al. (1987). Clinical and pathological evaluation of early gastric cancer and lymph node metastasis. Kurume Med. J. 34, 183-191.

Tanaka, M., Ashida, K., Umegaki, E. and Ohshiba, S. (1993). Endoscopic resection: For the purpose of a curative treatment of early gastric cancer. Stomach and Intestine 28, 87-98. (in Japanese)

Toyonaga, A., Harada, H., Ohmagari, K., Sasaki, E., TANIKAWA, K. et al. (1993). Endoscopic laser therapy for early gastric cancers. Stomach and Intestine 28, 99-106. (in Japanese) 